\title{
Personality Assessments in Architects' Offices: An Empirical Investigation of the Relationship between Personality Types, Forms and Productivity in Office Interior
}

\author{
Zahra Poursafar $^{1}$, Lewlyn L. R. Rodrigues ${ }^{2} \&$ Nandineni Rama Devi ${ }^{3}$ \\ ${ }^{1}$ Research scholar, Faculty of Architecture, Manipal University \\ 2 Professor, Head, Dept. of Humanities \& Management, Manipal University \\ ${ }^{3}$ Professor, Faculty of Architecture, Manipal University \\ Correspondence: Zahra Poursafar, Faculty of Architecture, Manipal Institute of Technology, Manipal University, \\ Manipal, India. Email: z.poursafar@yahoo.com
}

Received: August 15, 2016

doi:10.5539/mas.v11n1p235
Accepted: September 11, 2016

Online Published: November 22, 2016

\begin{abstract}
Purpose; this is an empirical research, concerned with the relationship between Personality types and Form of the Furniture, with the productivity consideration. The outcome does not emphasize the interactional processes among employees; it will establish a link between Psychology, Architecture and Productivity.

Methodology; the primary data for the survey was collected from a self-administered questionnaire from 202 employees through the online survey and hard copy. The survey study was conducted to the employees of the Architect's office in Iran and India.

Result; the study revealed that Personality types in Architects' offices has a significant influence on the employees' preferences regarding Form of the Furniture, but it had not impacted on their Productivity. Besides, Form selections in these offices had a significant influence on the employees' Productivity.
\end{abstract}

Keywords: personality types, architects' offices, form, furniture, productivity

\section{Introduction}

Designing of the Form in the work environment is an important issue due to the fact that the individuals' experience of Form has impacts on their perception of the environment. Form is the strong element of design, which refers to everything with shape, size, colour and texture that occupies space, marks position and indicates direction (Wong, 1993).

Form in interior design might describe the outline of the solids (the walls, ground and ceiling) and can define the filling objects (Furniture) which are used for these created empty spaces. Among all these Forms of the Furniture in the individual workstation is the primary concern of this research.The study hypothesized the individuals' perception about the Form of the Furniture in the work environment is changing according to their Personality differences.

Architects' office is a place or set of rooms in which architectural activities related to drawing, planning and consulting are taking place. Personality assessment is helpful in any offices for describing and predicting employees' behaviours, functionality and overall outcomes in the organizations (Ones et al., 2007).

Being aware about the Personality types is important in Architects' offices, because;

Applying the Personality assessment for personnel selection has become popular among the organizations (Anderson, 2007), due to the fact that different Personality types have different potential and internal abilities for undertaking different jobs. Personality assessment provided a data-based and non-subjective approach (Anderson, 2007) to determine high-potential employees who are properly fitted to the architectural practices in the offices.

Creativity is an important factor in these offices, simply because successful architectural projects must embrace both aesthetic and utilitarian, so architects need creative minds and proper skills. Many researche indicated that creativity is affected by Personality types (Prabhu et al., 2008; Meneely \& Portillo, 2005; Houtz et al., 2003; Helson, 1999; Sheldon, 1995). 
In connection with this matter, the present study investigated the importance of Personality types in the Architects' offices from the architectural perspective. The research focused on the influence of Personality types in Myers-Briggs model on architects' preferences and selections regarding Form of the Furniture in their individual workstations. Also influence of employees' Personality types and their preferences on productivity will be examined through statistical methods. Hence, the outcome of this research will be a significant contribution to the field of Architecture as no evidence is available on studies specifically focused on psychological influences of Form in Architects' offices.

\section{Literature Review}

Personality is an important concept in psychology, which may be identified as particular combination of the individual's emotional, behavioural and attitudinal pattern in different situations (Sandhu \& Kapoor, 2013). Portillo (2002) conducted an exploratory study to compare the Personality of interior designers, architects, landscape architects, and engineers. Results indicated that each group was described with specific Personality traits.

People with similar Personality attributes will have similar preferences (Cantador et al., 2013), due to the fact that Personality impact on how people make their decisions (Nunes, 2012). The present study investigated the influence of Personality types in MBTI model on the employees' selections and preferences regarding the Form of the Furniture in Architects' offices.

As indicated by Shruti (2012) office Furniture includes desks, chairs, shelves, etc. These parts have a particular function in the office and have an impact on the Productivity of the employees. Matthews et al. (2010) did a study about the influence of Personality on Form in residential buildings. Their study revealed that there was a strong relationship between Personality type (MBTI) and three-dimensional Form in design choices made for the creation of personal home environments.

For office designers, Furniture is described as a basic facility which increases the attractiveness of the space. As indicated by Morrell and Duffy (2004) Office design and its related parameters can have an impact on productivity of staff and innovation and creativity in the workplace. Architects' offices are one of the most creative workplaces in the world. Productivity improvement in the Architects' offices is linked with the factors which affect and promote creative ability of workers.

The physical environment of the workplace is an important factor which is involved with the Productivity (Carnevale, 1992; Clements-Croome, 1997; Uzee, 1999; Hameed \& Amjad, 2009). As estimated by Brill (1992) improvements in the physical layout of the workspace might result in a 5-10 percent increase in employee productivity and productivity improvement has always been an organizational goal of high priority (Pushpakumari, 2008).

Productivity is affected by employee's satisfaction at work (Harter et al., 2002). Job satisfaction is dependent on employees' perception of fulfilment of their mental and physical requirements in relation with their work environment (Saiyaden, 1993). However, the contents of the present study are contributed to the matter of satisfaction, but this concept and other parameters relevant to performance and comfort are extraneous to the study.

\section{Aims and Hypotheses}

The aims of this study was to find out the influence of the employee's Personality types on their preferences regarding Form of the work Furniture. The study also investigates the influence of Form in the individual workstation of Architect's offices on Productivity of employees in Iran and India.

Thus, the objectives of the study include:

To identify the employees' Personality types according to Briggs Myers theory in the sample group

To determine the influences of Personality types in MBTI model on Form selections in office interior

To identify the influence of Form in the office interior on employees' Productivity.

Based on the literature review the relationship between Psychology, Form and Productivity can be conceptualized and depicted in Figure 1. 


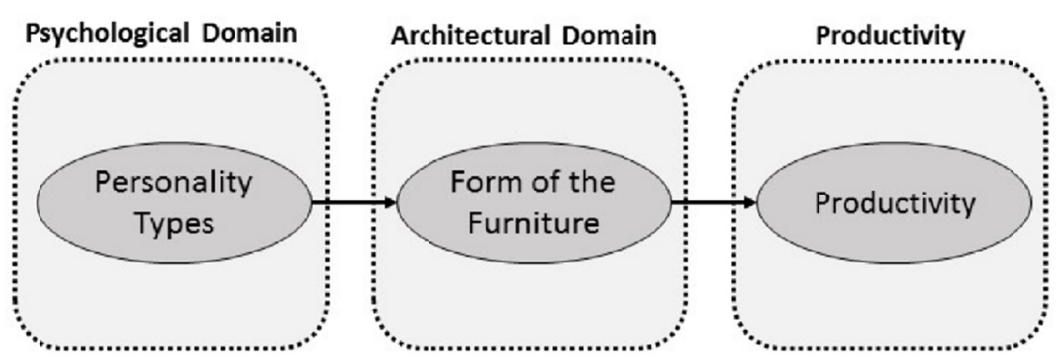

Figure 1. Conceptual model

Thus, this research study explores the following research hypotheses;

$\mathrm{H}_{1}$; Personality types in MBTI model has a significant influence on Form selection in office interior.

$\mathrm{H}_{2}$; Personality types in MBTI model has a significance influences on Productivity.

$\mathrm{H}_{3}$; Form selection in the interior design has a significant influence on Productivity.

\section{Method}

\subsection{Area of the Study}

The data collected for the survey was from two populated countries in Asia, Iran and India. The study investigated the relationship between Psychology -particularly Personality type-, Architecture and Productivity in the Architect's offices from both the countries. The Architect's office is an office which employs one or more architects and practices the profession of Architecture. The goal of these offices is to provide services (drawing, planning and consulting) in connection with the design and construction of buildings.

\subsection{Sample Size}

The sample size was chosen based on representative sampling technique, from 80 Architects' offices in Iran and India. In the second generation statistical technique sample size is not a major problem because the Smart PLS algorithm is designed in such a way that as long as the sample size is above 200 it can extrapolate it to any number based on Bootstrapping technique.

\subsection{Procedure}

A well-designed self- administered questionnaire was conducted to collect the primary data from 202 employees. The mode of delivery was both through online questionnaire and hardy copy form. The context was the Architect's offices, and the respondents were naturally aware about the physical and architectural elements of their workplace and thus provided the necessary information with ease.

The data, which is basically qualitative in nature was converted into the quantitative form through the Likert type 5-point scale. It is then processed using statistical packages SmartPLS version 3.0 and SPSS version 22. The results obtained through analysis were used to test the hypotheses of the study.

The questionnaire of the study consisted of four sections:

In the first part; demographic information was gathered from the 202 employees who answered the questionnaire. Their gender, age and education profile are asked in the first 3 questions.

The second part of the questionnaire was concerned with the 93 standard questions of Myers-Briggs scale, identifying the Personality types of the employees.

The third part of the questionnaire was concerned with the psychological trait particularly Personality types and their impact on Form selection in the office interior.

In the fourth part the attendees gave their subjective evaluation and perception regarding Form of the Furniture in their individual workstations.

Finally in the last three questions of the survey, attendees gave their opinion about Productivity in accordance with the Form context of their workplaces.

\section{Results}

Data collected from the first part of the questionnaire has been summarized in Table 1 . 
Table 1. Demographic Information $(\mathrm{N}=202)$

\begin{tabular}{lll}
\hline Nationality & Iranian & $46 \%$ \\
& Indian & $54 \%$ \\
\hline Gender & Male & $36 \%$ \\
& Female & $64 \%$ \\
\hline Age group & $<25$ & $38 \%$ \\
& $25-34$ & $46 \%$ \\
& $35-45$ & $11 \%$ \\
& $>45$ & $5 \%$ \\
\hline \multirow{2}{*}{ Education Profile } & Diploma & $7 \%$ \\
& UG & $52 \%$ \\
& PG & $35 \%$ \\
& Professional & $6 \%$ \\
\hline
\end{tabular}

According to the Table 1, most of the respondents in the survey are females (64\%). About $46 \%$ of the attendees are between 25 to 34 years old and $52 \%$ of the employees have at least an undergraduate degree.

The Myers-Briggs Type Indicator (MBTI) is a Personality instrument based on the Carl Jung system of Personality (Jung, 1923), which forms the basis of the Myers-Briggs Type Indicator (MBTI) assessment tool. The Myers Briggs model of Personality was developed by Katherine Briggs and Isabel Briggs Myers, and is based on four preferences; E or I (Extraversion or Introversion), T or F (Thinking or Feeling), S or N (Sensing or intuition), J or P (Judgement or Perception) (Myers \& McCaulley, 1985).

The different possible combination of preferences determines sixteen Personality types. Each type can be assigned an acronym (or formula) according to the first letters of the combination of the preferences in each of the four criteria. For example: ISTJ - Introvert Sensing Thinking Judging (Myers et al., 2009). Table 2 displays the distribution of the Personality types in the sample group.

Table 2. Distribution of the Personality types in the survey ( $\mathrm{N}=202)$

\begin{tabular}{|c|c|c|c|c|c|c|c|c|c|c|c|c|c|c|c|}
\hline$\underline{\underline{T}}$ & $\frac{\hat{\underline{x}}}{\underline{\mathbf{X}}}$ & $\begin{array}{l}\vec{T} \\
\mathbb{S}\end{array}$ & 곺 & $\stackrel{\hat{n}}{\Omega}$ & $\hat{\vec{Z}}$ & $\vec{D}$ & $\sum_{i=1}^{\vec{T}}$ & 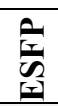 & $\stackrel{\vec{t}}{\mathbf{n}}$ & $\underset{E}{E}$ & $\stackrel{g}{2}$ & $\sum_{1}^{5}$ & $\sum_{i=1}$ & 疋 & 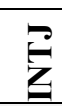 \\
\hline 1 & 8 & 7 & 20 & 8 & 7 & 48 & 25 & 7 & 7 & 7 & 26 & 7 & 11 & 4 & 9 \\
\hline
\end{tabular}

According to Table 2 all the 16 types were found in the survey. ESTJ was more frequent in the population followed by ISTJ. The result indicated that preferences of ' $\mathrm{T}$ ' and ' $\mathrm{J}$ ' are more frequent for the architects groups under the study. As indicated by Myers et al. (2009) people with the preferences of ' $T$ ' (Thinking) are objective and base their decision on hard logic and facts and individuals with preferences of ' $\mathrm{J}$ ' (Judging) have a tendency to be organized and prompt. According to the result of the survey, outlined in Table 2, architects are rational and logical people who have the organized approach to life.

The result of the three last parts of the questionnaire in the form of 'Liker scale' questions, deals with the influences of independent variables of the study -Personality types and Form selections- on dependent variables which are the Form selections and Productivity. The statistical result of this study is outlined via SmartPLS which is one of the prominent software relied upon the nonparametric bootstrap techniques. Figures 2 displays the structural model after running the PLS algorithm revealing the $\beta$ coefficients and R2 values for the dependent latent variables. 


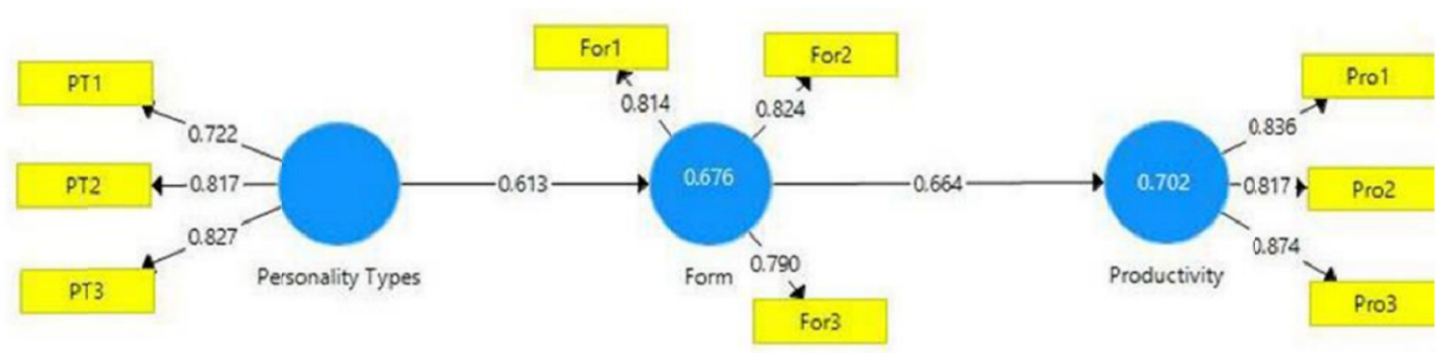

Figure 2. Structural model with path coefficients and R2 values

The hypothesised model with path coefficient and the explanatory power (R2) for each dependent construct is displayed in Figure 2. Path coefficients show the strength of relationship between the two latent variables and R2 shows percentage influences of independent variable on dependent variables which is a strong value in this model.

The present study investigated the relationship between variables of the study in three hypotheses. The result of the statistical analysis for $\mathrm{H} 1$ and $\mathrm{H} 2$ derived via SPSS is shown in Table 3.

Table 3. Two ways ANOVA

\begin{tabular}{lllllll}
\hline & DF & SS & MS & F & \multicolumn{1}{l}{ P } \\
\cline { 2 - 7 } $\mathrm{S}=0.0997$ & MBTI Personality Types-Form & 15 & 3.12491 & 0.208327 & 25.17 & 0.000 \\
\cline { 2 - 7 } & MBTI Personality Types- productivity & 1 & 0.02623 & 0.026230 & 3.17 & 0.095 \\
\cline { 2 - 6 } $2=96.21 \%$ R2 (adj) $=92.17 \%$ & & & & &
\end{tabular}

As Table 3 indicates Personality types do not have a significant influence on Productivity. But according to the table and values, Personality type has a statistically significant effect on the Form selection of employees in the Architect's offices. The third hypothesis of the study is tested through the regression test in Table 4.

Table 4. Regression result of models for influence of Form selection on Productivity

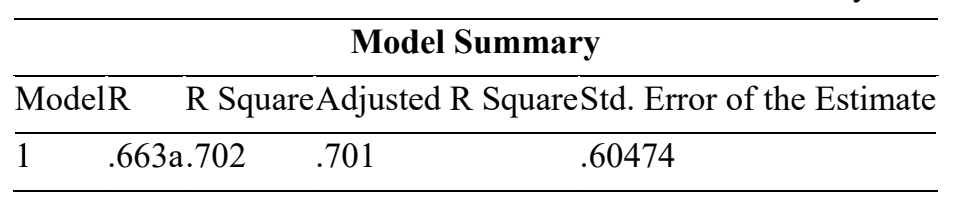

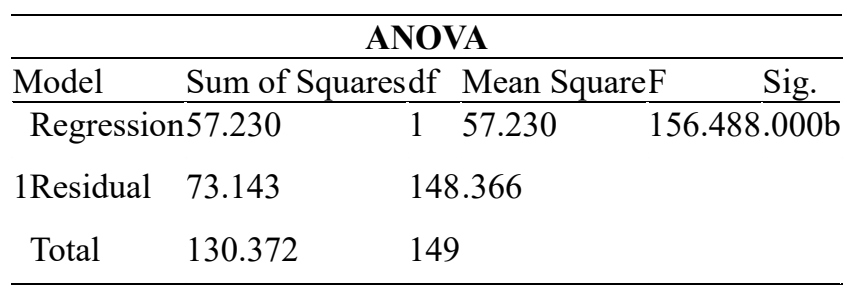

\begin{tabular}{llllll}
\hline \multicolumn{5}{c}{ Coefficients } & \\
\hline \multirow{2}{*}{ Model } & \multicolumn{4}{c}{ Unstandardized CoefficientsStandardized Coefficients } & Sig. \\
\cline { 2 - 4 } & $\mathrm{B}$ & Std. Error & Beta & & \\
\hline (Constant) & 1.026 & .233 & & 4.395 & .000 \\
1 & Form Selection.722 & .058 & .663 & 12.510 .000 \\
\hline
\end{tabular}


As indicated in Table 4, the coefficient of determination R. square $=0.702$. From this percentage, it is concluded that 70 percent of the variability of the employees' Productivity is accounted for by the variables in this model. The Regression Equation:

Productivity $=1.026+0.722$ Form selection

The significance value indicates that Form selection in the interior design has a significant influence on Productivity (at 5\% significance level). The results of the survey finalized hypotheses, which were set before the implementation of the study. Table 5 shows the overall result of hypotheses testing.

Table 5. The result of hypotheses testing

\begin{tabular}{ll}
\hline Hypotheses & Status \\
\hline H1; Personality types in MBTI model has a significant influence on Form selection & Supported \\
in office interior. & Rejected \\
H2; Personality types in MBTI model has a significance influences on productivity. & Supported \\
H3; Form selection in the interior design has a significant influence on productivity. & Sup
\end{tabular}

\section{Conclusion}

The research was investigated psychological influences in the workplace in terms of Personality types of employees, in connection to the physical features of work, particularly Form of the Furniture in the individual workstation. The analysis was implemented to the Architects' offices in Iran and India with the sample size of 202 employees.

The research was relied upon the importance of Personality types in the offices specially Architects' offices, due to the fact that Personality is related to human mind and impacts individual's perception and preferences regarding their workstation. According to the findings of the study Personality differences influences architects' selections in case of Form of the Furniture and these selections impact their productivity in their work environment.

The creation and preservation of an interior space are required to consider people preferences and attempt to increase the sense of well -being by attention to their personal opinions regarding working physical environment (Poursafar et al., 2016). Thus, the design of Architect's office is required to serious consideration of Personality type and individual's preferences, because this group is well aware about the quality of the spaces and utilization of their selections regarding workstation would enhance their satisfaction and overall Productivity in the workplace.

\section{Acknowledgments}

Authors are thankful to all the principals' architects of the organizations for giving permission to their employees for online and personal participation.

\section{References}

Anderson, M. G. (2007). Personality Assessment in Personnel Selection. Retrieved from https://www.cpp.com/pdfs/Personality_Assess_Personnel_Selection.pdf

Briggs, I. M. McCaulley, N. Q., \& Hammer, A. (1985). Manual: A guide to the development and use of the Myers-Briggs Type Indicator. Consulting Psychological Press.

Brill, M. (1992). Workspace design and productivity. In The Healthcare Forum Journal, 35(5), 51-53.

Cantador, I., Ignacio, F. T., \& Alejandro, B. (2013). Relating Personality types with user preferences in multiple entertainment domains. In CEUR Workshop Proceedings. Shlomo Berkovsky.

Carnevale, D. G. (1992). Physical settings of work: A theory of the effects of environmental form. Public Productivity \& Management Review, 423-436.

Clements, C., \& Derek, J. (1997). Specifying indoor climate. Naturally Ventilated Buildings, E \& FN Spon (Chapman \& Hall), ISBN 0419215204, 3591.

Hameed, A., \& Shehla, A. (2009). Impact of office design on employees productivity: a case study of banking organizations of Abbottabad, Pakistan. Pakistan. Journal of public affair, administration and management, 
$1-13$.

Harter, J. K., Frank, L. S., \& Theodore, L. H. (2002). Business-unit-level relationship between employee satisfaction, employee engagement, and business outcomes: a meta-analysis. Journal of applied psychology, $87(2), 268$.

Helson, R. (1999). A longitudinal study of creative Personality in women. Creativity Research Journal, 12(2), 89-101.

Houtz, J. C., Edwin, S., Giselle, B. E., Ruth, A. O., Kristen, M. P., \& Donald, J. T. (2003). Creativity styles and personal type. Creativity Research Journal, 15(4), 321-330.

Jung, C. G. (1923). Psychological types: or the psychology of individuation. Harcourt, New York.

Matthews, C., Caroline, H. F., Duncan, C., \& Tom, A. (2010). Personal Bias: The Influence of Personality Profile on Residential Design Decisions. Housing and Society, 3(1), 1-24.

Meneely, J., \& Margaret, P. (2005). The adaptable mind in design: Relating Personality, cognitive style, and creative performance. Creativity Research Journal, 17(2-3), 155-166.

Mitton, M., \& Courtney, N. (2011). Residential interior design: A guide to planning spaces. John Wiley \& Sons.

Morrell, P., \& Duffy, F. (2004). The impact of office design on business performance. Published by the Commission for Architecture \& the Built Environment and the British Council for Offices.

Myers, I. M., McCaulley, N. Q., Hammer, A., \& Mitchell, W. (2009). MBTI Step III manual: Exploring Personality development using the Myers-Briggs Type Indicator instrument. Mountain View, CA: CPP.

Nunes, M. A. S. N, \& Rong, H. (2012). Personality-based recommender systems: an overview. In Proceedings of the sixth ACM conference on Recommender systems, 5-6. ACM.

Ones, D. S., Stephan, D., Chockalingam, V., \& Timothy, A. J. (2007). In support of Personality assessment in organizational settings. Personnel psychology, 60(4), 995-1027.

Portillo, M. (2002). Creativity defined: Implicit theories in the professions of interior design, architecture, landscape architecture, and engineering. Journal of Interior Design, 28(1), 10-26.

Poursafar, Z., Nandineni, R. D., \& Rodrigues, L. R. (2016). Evaluation of color and lighting preferences in architects' offices for enhancing productivity. International Journal of Current Research and Review, 8(3), 1.

Prabhu, V., Charlotte, S., \& William, S. (2008). Creativity and certain Personality traits: Understanding the mediating effect of intrinsic motivation. Creativity Research Journal, 20(1), 53-66.

Pushpakumari, M. D. (2008). The impact of job satisfaction on job performance: An empirical analysis. In City Forum, 9(1), 89-105.

Saiyaden, M. A. (1993). Human Resource Management. McGraw-Hill. New Delhi.

Sandhu, T., \& Shaina, K. (2013). Implications of Personality types for emotional regulation in young women. Personality Types for Emotional Regulation, 1(4), 34-39.

Sheldon, K. M. (1995). Creativity and self-determination in Personality. Creativity Research Journal, 8(1), 25-36.

Shruti, S. (2012). Relationship between work environment and Productivity. Int J Engin Res Appl (IJERA), 2(4), 1992-5.

Uzee, J. (1999). The inclusive approach: creating a place where people want to work. Facility Management Journal of the International Facility Management Association, 26-30.

Wong, W. (1993). Principles of form and design. John Wiley \& Sons.

\section{Copyrights}

Copyright for this article is retained by the author(s), with first publication rights granted to the journal.

This is an open-access article distributed under the terms and conditions of the Creative Commons Attribution license (http://creativecommons.org/licenses/by/4.0/). 